\title{
Nucleoside Recognition by a Fluorescent Macrolactam
}

\author{
Hae-Jo Kim ${ }^{*}$ and Jong-In Hong," \\ Department of Chemisty, College of Natural Sciences, Kyonggi University, Stwon 443-760, Korea. "E-mail. haejkim@kgu.ack \\ ${ }^{\dagger}$ Department of Chemisty, College of Natural Sciences, Seoul National University, Seoul 151-747, Korea \\ "E-mail: jihong@snu,ac.kr \\ Received Angust 16, 2007
}

Key Words : Fluorescence, Macrolactam, Nucleoside, Recognition

Molecular recognition of nucleosides or nucleotides is attracting a great deal of interest due to their genetic functions in living organisms. ' Hydrophilic nature of nucleosides and nucleotides allows only a conformationally well defined receptor to form a hydrogen-bonded, electrostatic or hydrophobic complex with nucleosides or nucleotides in water. ${ }^{2}$ Recently, an anthracene derivative was reported to show a higher affinity toward GTP over ATP owing to cooperative interactions of hydrogen bonding and electrostatic interactions between an imidazolium moiety and a phosphate unit. $^{3}$

We have developed various sugar receptors with hydrogen-bonding acceptors and donors. ${ }^{4}$ Herein, we report a novel $D_{2}$-symmetric fluorescent macrolactam. This host possesses not only an aromatic cavity for $\pi-\pi$ interaction, but also hydrogen-bonding donors/acceptors in the peripheral site of the macrolactam for effective nucleoside recognition.

Macrolactam host was synthesized via the typical acid chloride coupling metho ${ }^{5}$ in which 2,5-dimethyl- $p$-xylyldiamine was treated with 2,5-dimethoxyterephthaloyl chloride in a high dilute condition to afford the desired 2:2 macrocyclization product $(\mathbf{H})$. The calculated structure shows that the host has a large cavity with dimension of $10.5 \AA \times 6.9 \AA$ (Fig. 1. left). The global minimum structure clearly indicates that $\pi$ - $\pi$ stacking interaction exists between the dimethoxy aryl groups of $\mathbf{H}$ and the uracil base of uridine with aromatic-aromatic surface distances of 3.56 and $3.55 \AA$, and one intermolecular $\mathrm{H}$-bonding interaction also exists between the carbonyl group of $\mathbf{H}$ and 2 $-\mathrm{OH}$ group of uridine (Fig. 1. right). ${ }^{7}$

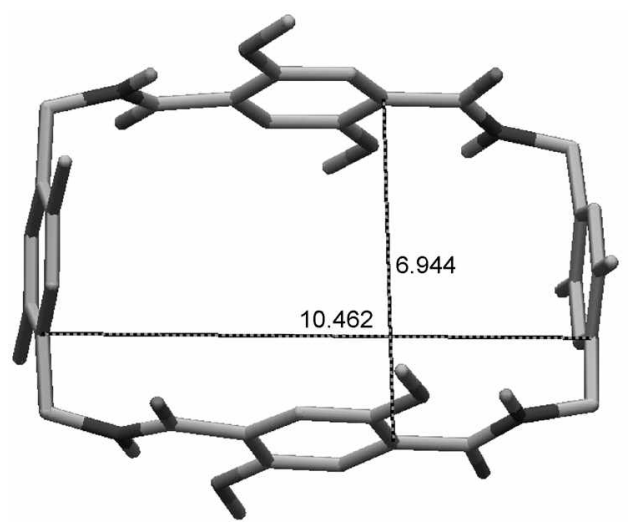

Owing to the characteristic fluorescence property of $\mathbf{H}^{8}$ fluorescence titration was carried out in chloroform. Fluorescence emission intensities at $\lambda_{\max }=384 \mathrm{~nm}$ were recorded after excitation at $\lambda_{\mathrm{ex}}=331 \mathrm{~nm}$ (Fig. 2). Fluorescence intensities of the host-guest complex increase upon addition of sugars or nucleosides presumably due to the restricted rotation of $\mathbf{H}^{9}$ The resulting fluorescence enhancements at $384 \mathrm{~nm}$ are shown in the inset of Figure 3. The binding stoichiometry between $\mathbf{H}$ and guests was also confirmed to be $1: 1$ by Job's plot (Fig. 4). ${ }^{10}$

Curve fitting of the host signals to a 1:1 binding isotherm gives apparent dissociation constants of up to $K_{d}=10^{-4} \mathrm{M}$, which are summarized in Table 1.

While the dissociation constants between $\mathbf{H}$ and anomers of D-glucose were found to be similar $\left(3.99 \times 10^{-4} \mathrm{M}\right.$ for $\beta$

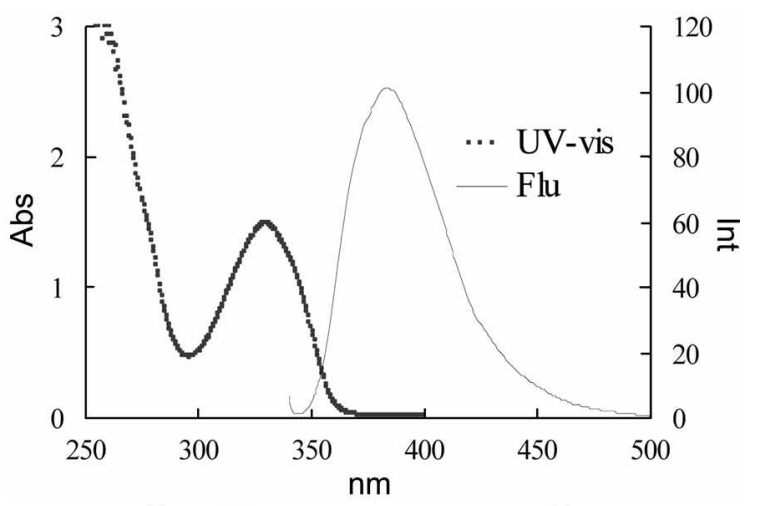

Figure 2. UV-vis and fluorescence spectra of $\mathrm{H}$ in $\mathrm{CHCl}_{3}$ at $298 \mathrm{~K}$.

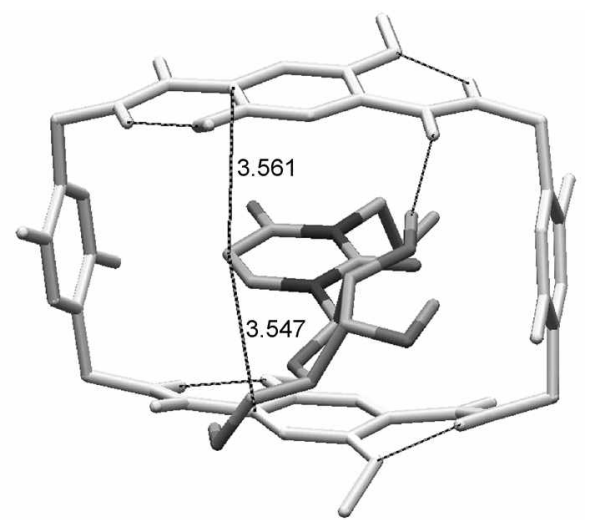

Figure 1. Global minimum structures of $\mathbf{H}$ (left) and its uridine complex (right). 


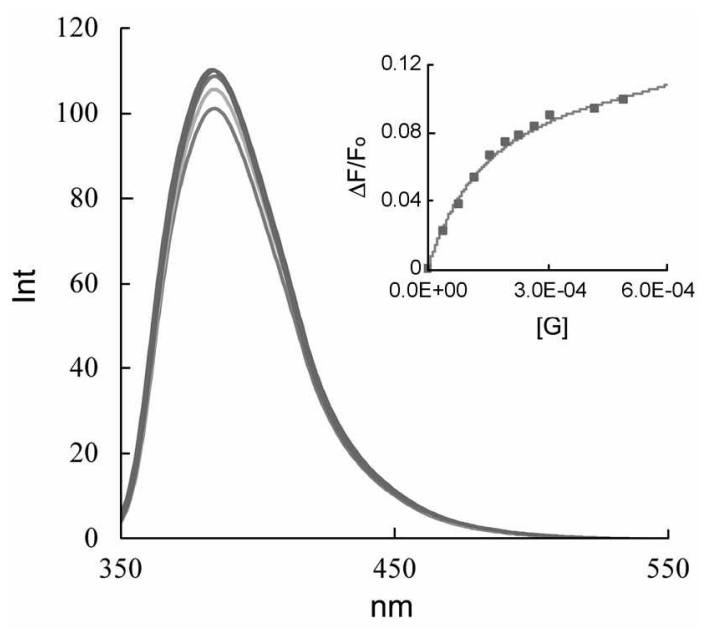

Figure 3. Fluorescence titration of $\mathbf{H}$ and uridine in $\mathrm{CHCl}_{3}$ at 298 $\mathrm{K} .[\mathrm{H}]=2.0 \mu \mathrm{M}$.

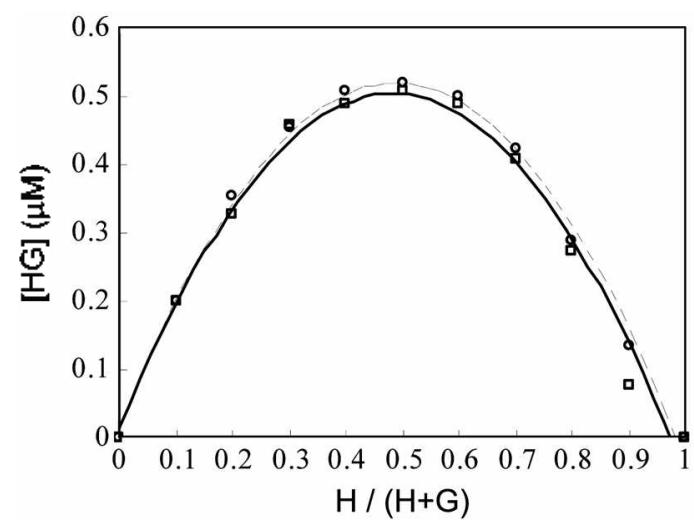

Figure 4. Job's plot between $\mathbf{H}$ and D-glucopyranosides at $298 \mathrm{~K}$. $[\mathrm{H}]+[\mathrm{G}]=2.0 \mu \mathrm{M}$, each in $2.0 \mathrm{~mL}$. Rectangular and circle represent $\beta$-glucose and uridine, respectively.

and $5.38 \times 10^{-4} \mathrm{M}$ for $\alpha$ anomer), the binding affinity of $\mathbf{H}$ to $\beta$-galactose is three times lower than that of $\beta$-D-glucose $\left(1.31 \times 10^{-3} \mathrm{M}\right.$ for $\beta$-D-galactose). This diastereoselectivity for sugars plausibly results from the slight energetic difference in the internolecular H-bonding patterns due to the varying degree of steric interaction between sugars and $\mathbf{H}$. This indicates that geometrical complementarities of $\mathrm{H}^{-}$ bonding partners are crucial in hydrogen bond-based molecular recognition system.

It is noticeable that nucleosides, deoxythymidine (d-Thy) and uridine (Uri) show the comparable binding affinities although they have fewer number of hydroxyl groups compared with the pyranosides. Uridine shows much higher binding affinity $\left(1.72 \times 10^{-4} \mathrm{M}\right)$ than $\beta$-D-glucose. Enhancement in the binding affinity for nucleosides probably results from the presence of $\pi$-surface and $\mathrm{H}$-bonding donors and acceptors in the guests.

It is assumed that $\pi-\pi$ stacking interaction between $\mathbf{H}$ and nucleosides plays an important role in host-guest binding. We have chosen several commercially available aromatic guests to test this assumption. While benzene is weakly bound to $\mathbf{H}\left(K_{d}=4.05 \times 10^{-2} \mathrm{M}\right)$, the binding affinity of a $\pi$
Table 1. Dissociation constants between $\mathbf{H}$ and guests

\begin{tabular}{llll}
\hline entry & name & $\mathrm{K}_{\mathrm{d}}(\mathrm{M})$ \\
\hline & & \\
& & \\
& & \\
\end{tabular}

${ }^{a}$ Fluorescence titration of constant host concentration $(2.0 \mu \mathrm{M})$ in $\mathrm{CHCl}_{3}$ at $298 \mathrm{~K}$. Fluorescence intensily at $\lambda_{\text {em }}=384 \mathrm{~mm}\left(\lambda_{e x}=331 \mathrm{~nm}\right)$ was monitored after each addition of guest.

basic guest 1,4-dimethoxybenzene was $c a$. hundred times enhanced $\left(5.26 \times 10^{-1} \mathrm{M}\right)$. The binding affinity of a $\pi$ acidic guest dimethylterephthalate, however, was too small to deternine.

In conclusion, we have developed a novel fluorescent macrolactam as an artificial receptor for nucleosides. The receptor has shown high diastereoselectivity for sugars and even higher affinities for nucleosides due to the intenmolecular $\pi-\pi$ stacking interaction as well as $\mathrm{H}$-bonds between the macrolactam and sugars/nucleosides.

\section{Experimental}

Acid chloride synthesis. To a solution of $400 \mathrm{mg}$ (1.77 mmol) of 2,5-dimethoxyterephthalic acid in $20 \mathrm{~mL}$ of dichloromethane was added cat. amount of DMF and 2.0 $\mathrm{mL}$ of $2 \mathrm{M}$ oxalic acid chloride in dichloromethane (2 eq. ex., $4.0 \mathrm{mmol}$ ). Resulting white suspension was stirred at it

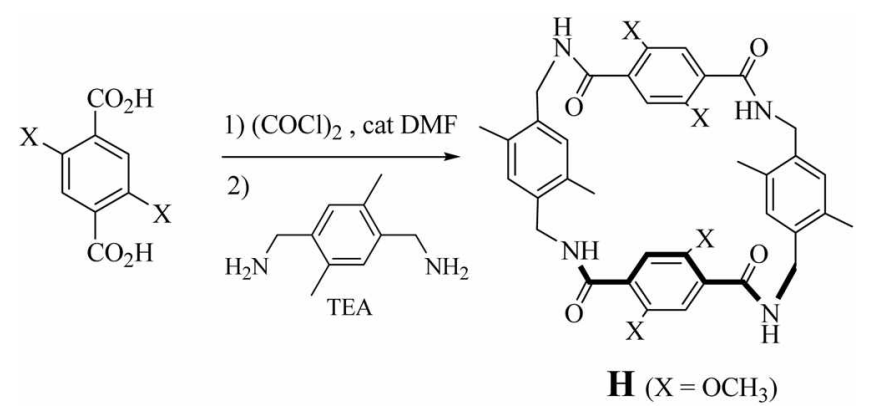

Scheme 1. Synthetic scheme of macrolactam. 
under nitrogen for $5 \mathrm{hrs}$ to afford a yellow clear solution. All volatiles were removed under the reduced pressure, dried in vacuum.

Cyclization. To a solution of p-xylyl diamine (1 eq. 1.77 mmol) and TEA (2 eq ex.) in $500 \mathrm{~mL}$ of dichloromethane was dropwise added a solution of above crude 2,5-dimethoxyterephthaloyl chloride in $50 \mathrm{~mL}$ of dichloromethane at 0 ${ }^{\circ} \mathrm{C}$ under nitrogen over a period of $2 \mathrm{hrs}$. Resulting yellow solution was stirred for additional $24 \mathrm{hrs}$ under nitrogen. All volatiles are removed under reduced pressure and purified by column chromatography. Column chromatography on silica gel $\left(\mathrm{CH}_{2} \mathrm{Cl}_{2}: \mathrm{MeOH}=10: 1, R_{\mathrm{f}}=0.48\right)$ gave a greenish mixture. Additional column chromatography on silica gel (EtOAc, $R_{\mathrm{f}}=0.30$ ) gave the desired product, $\mathbf{H}$ as a white solid in a $4.2 \%$ yield.

${ }^{1} \mathrm{H}-\mathrm{NMR}\left(300 \mathrm{MHz}, \mathrm{CDCl}_{3}\right): 8.09(\mathrm{t}, J=6.3 \mathrm{~Hz}, 4 \mathrm{H}$ of $\mathrm{NH}), 7.68\left(\mathrm{~s}, 4 \mathrm{H}\right.$ of $\mathrm{ArH}_{a}$ in 2,5-dimethoxybenzene), 7.06 (s, $4 \mathrm{H}$ of $\mathrm{ArH}$ in p-xylylene), $4.51(\mathrm{~d}, J=6.3 \mathrm{~Hz}, 8 \mathrm{H}$ of $\left.\mathrm{ArCH}_{2} \mathrm{~N}\right), 3.90\left(\mathrm{~s}, 12 \mathrm{H}\right.$ of $\left.\mathrm{OCH}_{3}\right), 2.29\left(\mathrm{~s}, 12 \mathrm{H}\right.$ of $\left.\mathrm{ArCH}_{3}\right)$.

UV-vis $\left(\mathrm{CHCl}_{3}\right): \approx_{331 \mathrm{~nm}}=3997 \mathrm{M}^{-1} \mathrm{~cm}^{-1}$, Fluorescence $\left(\mathrm{CHCl}_{3}\right): \lambda_{\mathrm{en}}=384 \mathrm{~nm}\left(\lambda_{\mathrm{ex}}=331 \mathrm{~nm}\right)$ in $2.0 \mu \mathrm{M}$

Mass $\left(\mathrm{FAB}^{+}, \mathrm{m}-\mathrm{NBA}\right): m / 2709([\mathrm{M}+\mathrm{H}], 50 \%)$

Acknowledgement. Financial support from Korea Research Foundation (KRF-2006-312-C00592) is greatly acknowledged.

\section{References}

I. (a) Yang, F.; Belitsky, J. M.; Villanueva, R. A.; Dervan, P. B.; Roth. M. J. Biochenistry 2003, 42, 6249. (b) Gearhart, M. D.; Dickinson, L.; Ehley, J.; Melander, C.; Dervan, P. B.; Wright, P. E.; Gottesfeld, J. M. Biochemistry 2005, 44, 4196.

2. (a) Urbach, A. R.; Dervan, P. B. Proc. Nat'l Aca. $\$$ ci. 2001, 98 , 4343. (b) Chenoweth, D. M.; Viger, A,; Dervan, P. B. J. Am. Chem. Soc, 2007, 129, 2216.

3. Kwon, J. Y.; Singh, N. J.; Kim, H. N.; Kim, S. K.; Kim, K. S.; Yoon, J. J. Am. Chem. Soc. 2004, 126, 8892.

4. (a) Cho. H. -K.; Kim, H. -J.; Lee, K. H.; Hono. J.-J. Bull. Korean Chem. Soc. 2004, 25, 1714, (b) Lee, D. H.; Kim, H.-J.; Hong, J.-I. Stipram. Chem, 2007,19,251.

5. Kim, H.-J.; Kim, Y.-H.; Hong, J.-I. Tetrahedron Lett, 2001, 42, 5049.

6. Kim, T. W.; Hong, J.-I. Bull. Korean Chem. Soc. 1995, 16, 781.

7. Conformation searches were performed with the program MacroModel 7.0, Amber* force field in chloroform solvent: Mohamadi, F.; Richards, N. Gi J.; Guida, W. C.; Liskamp, R; Lipton, M.; Caufield, C.; Chang G.; Hendrickson, T.; Still, W. C. J. Coniput. Chem. 1990, $11,440$.

8. (a) Jang. Y. J.; Jun, J. H.; Swamy, K. M. K.; Nakamura, K.; Koh, H. S.; Yoon, Y. J.; Yoon, J. Bull. Korean Chem. Soc. 2005, 26, 204 I. (b) An, B.-K.; Kwon, S.-K.; Park, S. Y. Bull. Korean Chem. Soc, 2005, 26, 1555

9. (a) Lee, D. H.; Im, J. H.; Lee, J.-H.; Hong, J.-I. Tetrahedron Lett. 2002, 43,9637. (b) Mcfarland, S. A.; Finney, N. S. J. Ant. Chent. Soc. 2002, 124, 1178 .

10. Job, P. Ann. Chim. 1928, 9, 113. 